\title{
ENSINO DE GEOGRAFIA E RESISTÊNCIA CAMPONESA EM UMA TRINCHEIRA DO SEMIÁRIDO BAIANO, BRASIL
}

\author{
Guilherme Matos de Oliveira ${ }^{1}$ \\ Universidade Estadual do Sudoeste da Bahia
}

Recibido 07/02/2021 Aceptado 20/05/2021

Este texto tem o objetivo de elucidar nossa experiência docente nos percursos do Ensino de Geografia do campo no município de Anagé-Bahia, Brasil; apontando sua relevância nos processos de resistência camponesa diante do avanço contraditório do atual modo de produção em seus espaços, e tendo como aporte metodológico discussões teóricas acerca da temática em questão, bem como apontamentos reflexivos sobre a significativa contribuição de nossas práticas de ensino tanto com a aprendizagem de nossos estudantes camponeses quanto com as estratégias destes sujeitos na convivência com o semiárido, e na defesa pela garantia dos seus modos de vida e trabalho socializados em suas trincheiras territoriais.

5 This text aims to elucidate our teacher experience in the teaching Geography in the field in the municipality of Anagé-Bahia, Brazil; pointing out its relevance in the processes of peasant resistance in the face of the contradictory advance of the current mode of production in their spaces, and having as methodological support theoretical discussions about the theme in question, as well as reflective notes on the significant contribution of our teaching practices so much with learning of our peasant students as with strategies of these subjects in living with the semiarid, and in defense for the guarantee of their socialized ways of life and labor in their territorial trenches.

DOI

https://doi.org/10.15366/didacticas2021.24.004

PALABRAS CLAVE

Camponeses; Educação do Campo; Ensino de Geografia.

1.ggui995@gmail.com $\uparrow \quad$ Peasants; Field Education; Teaching Geography. 


\section{INTRODUÇ̃̃O}

Nos percursos da realidade educacional brasileira, e em específico da Educação do Campo, o ensino de Geografia vem a ser um componente seminal para que a aprendizagem obtida na escola possa ter relevância aos seus estudantes; uma vez que as relações entre os conteúdos trabalhados em sala de aula e o cotidiano da vida social das crianças e jovens do campo podem ser estabelecidas de maneira concreta e significativa ao repercutirem nas trajetórias de seus sujeitos tanto no âmbito da formação educacional e escolar quanto no trabalho agrícola objetivado socialmente na terra camponesa.

Compreender e vivenciar este contexto se torna indispensável aos professores de geografia das escolas do campo, na medida em que a produção do espaço agrário é marcada por uma polissemia de oposições entre as classes sociais que se reproduzem no campo, sendo que a classe dominante busca extrair da terra renda e lucro para manter o funcionamento do atual modo de produção, e a classe camponesa visa estar na terra para a garantia da realização dos seus modos de vida, de trabalho, de cultura, de posição/atuação política e de sociabilidade, ao tempo em que esses propósitos distintos vão configurando desigualmente os territórios camponeses, cabendo ressaltar que a dimensão educacional compõe efetivamente este processo.

Diante deste entendimento, este texto tem como objetivo elucidar nossa experiência docente no ensino de Geografia em uma escola do campo do município de Anagé, localizado no semiárido do estado da Bahia, Brasil, e de apontar suas contribuições diante da resistência social estabelecida nesse contexto frente ao avanço dos conflitos e das contradições das formas de sociabilidade capitalista que vão atingindo de modo prejudicial seu espaço escolar, seus sujeitos e a comunidade camponesa na sua totalidade.

Para tanto, nos pautamos metodologicamente em discussões teóricas sobre a temática em questão, contanto com o aporte bibliográfico de Freire (1996), Pontusckha et. al. (2009), Camacho (2012), Oliveira (2015), entre outros autores; bem como em apontamentos das atividades que constituímos em sala de aula com os estudantes camponeses e que nos auxiliam nas reflexões levantadas pelo presente texto. Assim, num primeiro momento nos debruçamos a pensar de um modo mais amplo sobre o ensino de Geografia no contexto educacional camponês e num segundo momento associamos este debate às particularidades do real concreto que se expressam entrelaçados em nossa prática docente.

\section{ENSINO DE GEOGRAFIA NO ESPAÇO EDUCACIONAL E DE RESISTÊNCIA DO} CAMPO

No decorrer do processo histórico, o campo brasileiro tem sido marcado pelas formas contraditórias de sociabilidade que são impulsionadas pelo sistema do capital, haja visto que nas relações atuais entre sociedade e natureza esse contexto se reproduz tanto no avanço do mercado - que em crise, busca se apropriar cada vez mais da terra camponesa 
e dos seus recursos naturais, degradando e expropriando as condições de vida ambiental e humana que se processualizam espacialmente, principalmente por meio do agronegócio - quanto nas estratégias de resistência realizadas pelos sujeitos do campo ante as dificuldades que passam como fome, pobreza etc. e que são impostas pelo processo expropriatório, ao tempo que o espaço agrário vai se configurando por meio das desigualdades existentes entre as classes e seus interesses de lucro e renda versus de vida e trabalho.

Frigotto (2010, p. 35) aponta que este modelo de sociabilidade desigual pode atingir também o espaço educacional como acontecia nas chamadas escolas rurais, sendo que elas eram vistas por grande parte da sociedade como "inferiores" em relação ao contexto escolar encontrado na cidade. Esse discurso ideológico sustentado pelo modo de produção nega, conforme o autor, a educação numa perspectiva emancipatória que tem o intuito de fomentar o acesso ao conhecimento histórico e social do mundo em que vivem seus sujeitos, bem como sua construção compartilhada, independente se estes estão no campo ou na cidade, mas que diante de uma leitura reflexiva da realidade podem a apreender no movimento de unidade na diversidade.

Diante desse dilema, por mais de vinte anos têm-se realizado no Brasil esforços conjuntos entre os movimentos sociais, universidades, escolas da educação básica dentre outras instituições e sujeitos, que partem do propósito que a educação é uma bandeira necessária à luta camponesa, e buscam discutir propostas que versem Por uma Educação do Campo em contrapartida às escolas rurais do país, que evidenciavam o modelo urbano de sociabilidade e reforçavam os ditames estabelecidos pelo capitalismo ao campo, na tentativa ideológica de afastar dos seus territórios a busca pela reprodução do campesinato.

Desde 1998, por meio da I Conferência Nacional por uma Educação Básica do Campo realizada em Luziânia-GO, um dos pressupostos defendidos e assumidos pelo movimento era de "[...] ser uma ação educativa no sentido da contra-hegemonia, capaz de contribuir com a promoção de profundas transformações na sociedade brasileira" (MOLINA, 2010, p. 137). Dessa maneira, é por meio do enfrentamento às adversidades que rondam o campo e seus espaços educacionais, que a atuação social se faz necessária.

Segundo Caldart (2012) este movimento tem pautado suas iniciativas tanto no que se concebe pelo campesinato, pela luta emancipatória pela educação do campo, e na busca pela elaboração e efetivação de políticas educacionais, partindo da Lei de Diretrizes e Bases da Educação (LDB) no 9394/1996, que se desdobra pelo Plano Nacional de Educação (PNE); e pelas Diretrizes Operacionais para as Escolas de Educação Básica do Campo de 2002; entre outras propostas e propósitos que levam em consideração as demandas da classe camponesa.

Vinculada a esse processo, a dimensão do ensino nos espaços educacionais do campo também precisa ser pensada de forma consonante, uma vez que os conhecimentos que são trabalhados em sala de aula devem estar contextualizados à realidade local/global dos estudantes camponeses. O ensino de Geografia se insere nessa dinâmica haja visto que os 
seus conteúdos, pautados numa compreensão crítica sobre a produção contraditória e relacional do espaço geográfico, contribuem para que os alunos associem as temáticas estudadas na escola ao cotidiano da vida social em que estão inseridos.

Estas aspirações segundo Moraes (1994, p. 122) devem estar relacionadas, sob o âmbito pedagógico, às propostas e discursos encaminhados desde a década de 1970 pela Geografia em sua perspectiva crítica. Para o autor, estes direcionamentos podem aproximar a teoria e a prática na constituição do ensino desta disciplina escolar, e ao mesmo tempo estimular uma ampla reflexão docente na qual assimile a importância desse processo e possa contribuir com sua materialização.

Pontusckha et al. (2009) sinalizam que no movimento de renovação da Geografia brasileira sob a perspectiva crítica de sua análise no campo científico, a Associação dos Geógrafos Brasileiros (AGB) desempenhou um relevante papel na promoção de debates que reconheciam a importância da dimensão do ensino na Geografia, visto que direcionava sua preocupação em como minimizar a compartimentação dos conteúdos físicos e sociais do espaço geográfico trabalhados na escola, bem como de diminuir a distância do ensino de Geografia com a conjuntura social, política e econômica nacional, situação esta que vinha sendo pensada no âmbito acadêmico. Ainda destacam que:

O movimento de renovação do ensino da Geografia nas escolas fez parte do chamado movimento de renovação curricular dos anos 80 , cujos esforços estavam centrados na melhoria da qualidade do ensino, a qual, necessariamente, passava por uma revisão dos conteúdos e das formas de ensinar e aprender as diferentes disciplinas dos currículos da escola básica. (PONTUSCKHA et al., 2009, p. 68).

Esse processo também tem agregado, sobremodo a partir dos anos 1990, a formação dos professores de Geografia e o seu exercício profissional na esteira de discussões e pesquisas acadêmicas, uma vez que diante das mobilizações de renovação da ciência geográfica e curricular da educação básica, torna-se necessário pensar criticamente e agir em defesa de uma realidade educacional liberta das amarras desiguais do mundo hodierno (PONTUSCKHA et al., 2009, p. 68).

Vale ressaltar que essas dinâmicas não estão distantes da realidade educacional do campo, tornando-se plausível discutir a contribuição do ensino de Geografia que considera as nuances contraditórias da realidade concreta na luta social para a reprodução dos sujeitos camponeses pela via da educação. Dessa maneira, “[...] o importante é aprender a pensar, a pensar a realidade e não pensar pensamentos já pensados. Mas a função do educador não acaba aí: é preciso pronunciar-se sobre essa realidade que deve ser não apenas pensada, mas transformada" (GADOTTI, 2003, p. 53).

Em consonância a isso, Costa e Santos $(2009$, p. 3) afirmam que o professor de Geografia possui a tarefa de ensinar seus estudantes ao incentivá-los a ler o mundo para que compreendam a realidade em que se reproduzem tendo como referência seu espaço de 
vivência. Partindo disso, o ofício docente deve ser iluminado por um processo de ensinoaprendizagem resultante de uma construção teórica e prática, ao passo que:

Se o professor de Geografia é o mediador no processo de formação do aluno, se a qualidade dessa mediação interfere nos processos intelectuais, afetivos e sociais do aluno, ele tem tarefas importantes a cumprir. [...] A formação de professores de Geografia, na concepção de profissional crítico reflexivo, deve ser uma formação consistente, contínua, que procure desenvolver uma relação dialética ensino-pesquisa, teoria-prática. (CAVALCANTI, 2002, p. 20-21).

De acordo com o pensamento de Saviani (1999), o ensino deve ser constituído no espaço escolar na perspectiva de que possam ser elucidadas informações que fomentem o amadurecimento intelectual dos alunos, sem desviar o interesse de levar em conta os conhecimentos que eles dispõem e que construíram no percurso de suas vidas, podendo assim despertar uma aprendizagem mais aberta, livre, e que valorize os modos de viver e conviver dos alunos no tempo e no espaço de cada um deles, visto que "Integrar o educando no meio significa deixá-lo descobrir que pode tornar-se sujeito na história” (VESENTINI, 1994, p. 37).

Esta cooperação metodológica ao ato de ensinar objetiva aliar conhecimentos diversos entre alunos e professores, de forma que se torne algo dinâmico na troca de conhecimentos e experiências vividas por ambos, no intento de construir um diálogo no qual todos apresentem suas diferentes formas de compreender o mundo, de acordo com o ponto de vista de cada um. É importante ressaltar que:

Este método que busca constantemente a vinculação entre educação e sociedade tem como ponto de partida a prática social, o professor e os alunos posicionam-se como agentes sociais diferenciados, que se encontram num nível diferente de compreensão, conhecimento e experiência, mas com o avanço no diálogo consegue-se um nivelamento no conhecimento de ambos. (LUCAS e KNUTH, 2009, p. 104).

Para que os alunos possam vislumbrar de uma forma mais ampla as relações estabelecidas entre sociedade e natureza, eles precisam ser instruídos com práticas de ensino que apontem as desigualdades geográficas, sem privá-los do direito de serem agentes conscientes e construtores do espaço em que vivem, e tendo participação no desenvolvimento do processo de transformação social, pois:

O educador que, ensinando geografia, "castra" a curiosidade do educando em nome da eficácia da memorização mecânica do ensino dos conteúdos, tolhe a liberdade do educando, a sua capacidade de aventurar-se. Não forma, domestica. Tal qual quem assume a ideologia fatalista embutida no discurso neoliberal [...] preponderantemente às situações em que os pacientes são as classes populares (FREIRE, 1996, p. 33). 
Mediante a perspectiva freireana, que apregoa a necessidade de um ensino que tenha como ponto de partida o vivido e o convivido pelos estudantes, torna-se essencial ao professor de geografia do campo pensar em práticas pedagógicas que levem seus alunos a refletirem sobre o espaço agrário e que os motivem a observar, descrever, comparar, interpretar, analisar, desenvolver relações etc. para que tenham autonomia em abstrair o conhecimento geográfico - sobretudo a partir das mediações estabelecidas entre sociedade e natureza - por meio de questões sociais como dinâmica populacional, economia, agricultura, industrialização, geopolítica; atreladas às condições físicas da terra: relevo, hidrografia, clima, vegetação, ecossistemas, entre outros. Nesse sentido:

Compreendemos que a importância da ciência Geográfica [...] com a educação do campo, está na capacidade de transformação que a Geografia contém, esta capacidade se deve ao fato da mesma possuir uma relação intrínseca com a realidade. A partir da realidade, a Geografia pode desenvolver no estudante-camponês a capacidade de interpretar criticamente a realidade com o objetivo de fomentar uma opção transformadora essa realidade. Assim, a geografia tem que propiciar aos educandos pensarem as relações socioterritoriais e as suas contradições de classe, inerentes a sua realidade (CAMACHO, 2011, p. 27).

Coadunados com este pensamento, Alves e Magalhães (2008) destacam que o professor de Geografia tem a missão de trabalhar os conteúdos de sua disciplina em sala de aula com os alunos camponeses, fazendo uma associação entre os conhecimentos populares do campo com os conhecimentos científicos que se ancoram nas dinâmicas da natureza e nas relações sociais. Eles podem ser explicados, por exemplo, na importância do cultivar a terra; tendo a finalidade de traçar uma ligação do camponês com os meios produtivos em sociedade e valorizando, dessa maneira, a sua atuação laboral no espaço em que se reproduz.

Sendo assim desvelamos, no próximo tópico, algumas das nossas ações de ensino na Geografia escolar camponesa do interior baiano brasileiro, buscando sistematizar notas sobre as práticas pedagógicas que constituímos em sala de aula, seus alcances, limites, percalços e possibilidades na compilação de um processo de ensino-aprendizagem aderente às dificuldades e superações na qual nossos estudantes camponeses enfrentam no dia-a-dia em vista da garantia da sociabilidade camponesa em seus territórios.

\section{ENSINAR GEOGRAFIA NO CONTEXTO ESCOLAR E DE RENITÊNCIA DO CAMPESINATO NO SEMIÁRIDO DE ANAGÉ-BA: DESAFIOS E ALTERNATIVAS}

As travessias do pensar e edificar o ensino de Geografia na Educação do campo brasileira são complexas e desafiadoras, uma vez que na construção de um proposta educacional e contextualizada desta disciplina é preciso considerar diversas questões que perpassam não somente pelo seu espaço escolar, mas que extrapolam seus limites e confluenciam todas as relações camponesas constituídas ao seu redor, estabelecidas tanto à nível estrutu- 
ral quanto conjuntural e que são atravessadas por diversas situações, sejam elas de dilemas e/ou de obstinações sociais.

No que tange às questões estruturais, vários são os impasses enfrentados pelas escolas do campo, seja na carência de uma formação inicial e continuada mais consolidada aos seus professores, na falta de recursos didáticos (livros, apostilas, mapas, maquetes etc.) que tratem sobre a questão agrária de uma forma mais aproximada à realidade local e que se articulem ao movimento mundial; bem como na precarização dos espaços físicos das escolas camponesas e na perda de recursos financeiros e materiais próprios, dentre outros problemas.

Em convergência a isso, também podemos elucidar algumas questões conjunturais como o fechamento/nucleação das escolas do campo, sendo esta uma expressão do estágio crítico do atual modo de produção que atinge os sujeitos que vivem no espaço agrário e dificulta a manutenção de sua condição social diante das políticas de reordenamento territorial impostas pelo Estado e pelo Capital. As propostas curriculares que vão forjando esses novos moldes educacionais no campo brasileiro são uma outra complicação conjuntural por estarem associadas à uma realidade distante da educação local que, consequentemente, desconsidera suas particularidades e reproduzem o discurso de "atraso" do campo para que este possa ser incorporado mais efetivamente ao movimento de acumulação capitalista.

O contexto educacional camponês do semiárido baiano encontra-se envolto nestas contradições, visto que suas transformações naturais e sociais não acontecem de maneira isolada, mas inseridas na amplitude das reconfigurações críticas do espaço geográfico, ao passo que "no campo, atualmente, temos uma série de questões que devem ser tratadas na escola, pois esta não poderá ficar indiferente a esses acontecimentos. E cabe a geografia um papel singular na discussão dessas questões em sala de aula" (CAMACHO, 2011, p. 33).

Buscando aproximar esses pressupostos à nossa prática docente, entre os meses de março de 2018 e fevereiro de 2019 estivemos atuando com a disciplina de Geografia nas turmas dos anos finais do Ensino Fundamental da extensão escolar camponesa do Centro Educacional Renato Viana no município de Anagé-Bahia, Brasil, que contava com aproximadamente sessenta alunos; à medida que ao longo do período letivo tratamos sobre os conteúdos geográficos propostos pela unidade escolar a cada uma de suas séries tendo como referencial o cotidiano da vida dos estudantes camponeses das turmas onde estávamos inseridos.

Residentes em diversas comunidades camponesas do entorno da escola, entre elas Capinado, Jardim II, Poços, Bom Sucesso, Riachão, Araticum; seus estudantes se reproduzem com seus familiares e com as pessoas vizinhas às suas casas seja na lavoura plantando e colhendo alimentos, na criação de animais, nos afazeres domésticos, nos estudos em casa, no lazer etc. Contudo muitos deles, diante da expropriação e da violência fomenta- 
da pelo sistema econômico vigente no campo, passam por constantes dificuldades: pobreza, fome, problemas de saúde, cognitivos e psicológicos, dentre outras que os levam, junto com os demais sujeitos locais, a se organizarem nos movimentos sociais de luta e de resistência camponesa na oposição aos ditames do atual modo de produção sobre seus territórios.

Estes dilemas foram elucidados em uma atividade que realizamos nas primeiras aulas de Geografia em uma das turmas da escola ${ }^{1}$, em que pedimos aos alunos que ilustrassem nos seus cadernos os percursos que fazem de casa à escola - sendo que dois dos desenhos estão apresentados nas figuras $1 \mathrm{a}$ e $1 \mathrm{~b}$ - e neles tiveram a oportunidade de expressarem como se reproduziam socialmente, apontando em seus traçados os contrários da vida no espaço camponês brasileiro.
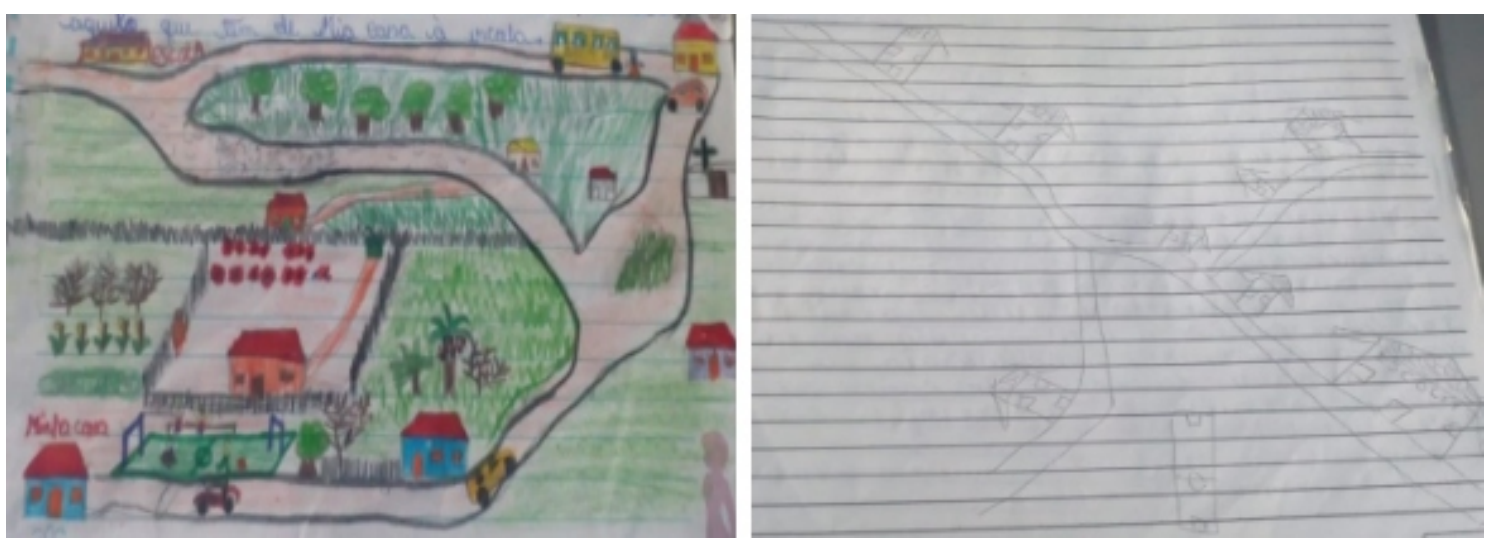

Figuras 1a e 1b: Ilustrações produzidas pelos estudantes. Fonte: Acervo do autor (2018)

À luz dos percursos reais e concretos destes estudantes, tecemos em nossas aulas estratégias didáticas que contemplassem o estudo sobre o espaço geográfico enfocando o campesinato brasileiro e local, haja visto que algumas das inúmeras ações de ensino desenvolvidas nas turmas da escola estão elencadas a seguir:

- $6^{\circ}$ ano: nele foram trabalhados conteúdos ligados aos aspectos físicos do espaço geográfico e de suas particularidades no que se refere ao campo anageense, que se encontra no bioma Caatinga, possui clima semiárido, vegetação xerófila (com cactos, mandacaru, umbuzeiros), passa por processos erosivos nos seus solos, é margeado hidricamente pelo rio gavião, e agrega em si outros elementos naturais; sendo que nessa turma pedimos aos alunos que, em forma de pesquisa, consultassem seus pais e avós sobre seus saberes climáticos, indagandoos quando são os períodos da seca, os períodos chuvosos, como eles interferem na produção agrícola, dentre outras informações que pudessem ser levadas à

1 Sobre o detalhamento dessa aula, ver Oliveira (2020). 
sala de aula e relacionadas com os dados disponibilizados pelos sites oficiais de meteorologia, à medida que:

\begin{abstract}
A opção por situar o saber popular no interior da proposta curricular, ao invés de utilizá-lo apenas como ponte para o saber erudito, favorece o amadurecimento de novas modalidades de organização curricular, o que aproxima o envolvimento do estudante com o planejamento de sua aprendizagem. Dessa forma, a educação geográfica contextualizada no projeto camponês de convivência com o semiárido rompe com a condição curricular da escola urbana, que reflete, quase sempre, os interesses de uma ideologia dominante. (OLIVEIRA, 2015, p. 52).
\end{abstract}

- $7^{\circ}$ ano: nele discutimos questões geográficas à nível brasileiro, abordando temas como população, agricultura, urbanização, industrialização, as cinco regiões, dentre outros, apontando seus desdobramentos em diversos recantos agrários do país e salientando, ao mesmo tempo, o papel histórico dos movimentos sociais do campo na formação do território nacional e de sua atual criminalização instituída pelo Estado. Partindo disso, solicitamos a cada aluno da turma que redigissem um texto amplo sobre a trajetória de lutas e resistência do Movimento dos Pequenos Agricultores (MPA) - um dos mais atuantes no município - consultando os seus participantes do movimento para que os auxiliassem, e que posteriormente reunissem seus escritos em um texto mais amplo, acessível para eles e toda a comunidade camponesa.

- $8^{\circ}$ ano: nessa turma foram tratados assuntos geográficos de âmbito continental, sobretudo em relação aos aspectos econômicos e sociais de produção desses espaços considerados 'periféricos' frente às demais áreas do globo, posto que estas nuances revelam a pujança histórica das lutas de classe no campo latino-americano, que nos levaram a pedir aos estudantes que organizassem um painel com o mapeamento dos inúmeros movimentos históricos de ação política do campesinato na América Latina, e destacando nele a ampla participação dos movimentos sociais à nível brasileiro, baiano e local nos itinerários temporais e espaciais de organização política em nosso continente.

- $\quad 9^{\circ}$ ano: a esta turma foram propostos estudos sobre o espaço geográfico na sua totalidade-mundo, sendo que seus conteúdos versam sobre as determinações dos espaços 'centrais' na unidade das contradições do sistema capitalista, ao tempo em que o agronegócio tem contribuído com as articulações deste processo. Diante disso, requisitamos aos estudantes que trouxessem à sala de aula destaques jornalísticos sobre a produção agrícola em nosso país para a realização de um debate, e nele trocamos informações sobre a conversão dos produtos primários em commodities - mercadorias exportadas para vários países bem como as implicações desse processo à soberania e segurança alimentar 
nacional e dos seus impactos ambientais (poluição, desmatamento, queimadas) e sociais (doenças, violência, espoliação) decorrentes das imposições do mercado.

Para além dessas ações didáticas concebemos outras metodologias de facilitação dos conteúdos da disciplina às situações vividas pelos nossos estudantes por meio de jogos, seminários, trabalho de campo etc., enfocando principalmente o 'chão' camponês onde a escola e seus alunos estão presentes ao tratarmos das variadas estratégias desses sujeitos na convivência com o semiárido, seja:

- No armazenamento de água da chuva que realizam com as cisternas e de sua utilização (seja no consumo doméstico, na irrigação de cultivos diversos, para as plantas e animais, entre outras demandas);

- No compartilhamento e formação de bancos de sementes crioulas entre as famílias e as comunidades em que fazem parte;

- Na leitura analítica sobre as dificuldades vividas no labor da roça (principalmente nas épocas de seca), e a consequente mobilidade dos seus trabalhadores para as cidades;

- Nas dificuldades de organização comunal da luta pela/na terra local, bem como suas expressões territoriais de resistência política e cultural (com as festas juninas e os ternos de reis no Natal) dentre outros notáveis processos, ao passo que:

[...] os desafios estão no horizonte e as soluções estão no nosso caminhar, no nosso plantar, no nosso colher, no nosso trabalho, na nossa luta, na nossa história e na nossa geografia. Quando geografamos, fazemos nossos territórios e construímos nossas histórias. Esta é a Pedagogia da Educação do Campo. A Pedagogia dos sujeitos que fazem de seus territórios os seus pensamentos e os defendem. (FERNANDES, 2012, p. 16).

Diante do exposto, verificamos o quão plausível tem sido o ensino de Geografia nos espaços da Educação do Campo no semiárido anageense haja visto que, conforme nossa experiência docente, vem permitido por meio da relação ensino-aprendizagem uma consistente mediação dos postulados teóricos da disciplina às dinâmicas espaciais dos nossos estudantes; ao tempo em que as práticas pedagógicas que desenvolvemos com eles foram sistematizadas especialmente na feitura e utilização de procedimentos e recursos didáticos que viabilizaram as atividades propostas tanto em sala de aula quanto fora dela.

\section{CONSIDERAÇÕES FINAIS}

As análises engendradas neste texto nos revelam os caminhos do pensar e do agir do professor na Geografia escolar do campesinato, oportunizando-nos a vislumbrar as conquis- 
tas, obstáculos e estímulos de sua prática docente neste espaço educacional seja, por exemplo, na intenção de que seus estudantes possam superar uma visão determinista do senso comum sobre o campo semiárido, que o reduz a um "atrasado sertão de terra seca, rachada e inóspita”, pois a difusão deste pensamento ideológico tem proporcionado às atuais formas de sociabilidade capitalista a avançarem no espaço agrário, tensionando nele os conflitos e contradições próprias de seu sistema em crise.

Nesta direção, percebemos o potencial explicativo e prático da Geografia escolar do campo diante do nosso exercício docente no ensino e da sua significativa contribuição à aprendizagem dos nossos estudantes, em que vieram a adquirir uma gama de conhecimentos sobre a abrangência das modificações espaciais ao partirem das singularidades de onde se reproduzem, e que consequentemente repercutiram nos seus modos de vida e de renitência na terra de trabalho, à medida que as temáticas geográficas ao serem abordadas no ambiente escolar de maneira contextualizada vão fazendo sentido ao ser social camponês.

Posto isso, torna-se imprescindível agregar nossos anseios e ações enquanto práxis por um ensino de Geografia comprometido ao necessário reacender da luta em defesa dos espaços educacionais e sociais do campo no antagonismo ao avanço do modo de produção hodierno, tanto nas particularidades do semiárido de Anagé-BA quanto nos demais rincões agrários de nosso país mobilizando, mesmo que nos limites da resistência, os sujeitos que compõem este processo na busca pela emancipação humana e pela garantia de sociabilidade da classe camponesa em suas trincheiras territoriais.

\section{REFERÊNCIAS}

ALVES, Wellington Galvão; MAGALHÃES, Sandra Maria Fontenele. O ensino de geografia nas escolas do campo: reflexões e propostas. Revista da Casa da Geografia de Sobral, Sobral, v. 10, n. 1, p. 79-91, 2008.

CALDART, Roseli Salete. Educação do campo. In: CALDART, R. S. et al. (Orgs.). Dicionário da Educação do Campo. Rio de Janeiro, São Paulo: Escola Politécnica de Saúde Joaquim Venâncio, Expressão Popular, 2012, p. 259-267.

CAMACHO, Rodrigo Simão. A geografia no contexto da educação do campo: construindo o conhecimento geográfico com os movimentos camponeses. Revista Percurso, Maringá, v. 3, n. 2, p. 25- 40, 2011.

CAVALCANTI, Lana de Souza. Geografia e práticas de ensino. Goiânia: Alternativa, 2002.

COSTA, Cláudia Lúcia da; SANTOS, Rosselvelt José. Ensino de Geografia no campo: a importância do lugar no processo de ensino-aprendizagem. In: $10^{\circ}$ Encontro Nacional de Prática de Ensino de Geografia. Porto Alegre: UFRGS, 2009, p. 1-10. 
FERNANDES, Bernardo Mançano. Territórios da Educação do Campo. In: ANTUNESROCHA, M. I. et al. (orgs.). Territórios educativos na educação do campo: escola, comunidade e movimentos sociais. $2^{\mathrm{a}}$ ed. Belo Horizonte: Editora Gutenberg, 2012, p. 15-20.

FREIRE, Paulo. Pedagogia da Autonomia: saberes necessários à prática educativa. São Paulo: Paz e Terra, 1996.

FRIGOTTO, Gaudêncio. Projeto societário contra-hegemônico e educação do campo: desafios de conteúdo, método e forma. In: MUNARIN, A.; BELTRAME, S.; CONDE, S. F.; PEIXER, Z. I. (orgs). Educação do campo: reflexões e perspectivas. Florianópolis, 2010, p. 19-46.

GADOTTI, Moacir. Boniteza de um sonho: ensinar-e-aprender com sentido. Novo Hamburgo: Feevale, 2003.

LUCAS, Rosa Elane Antoria; KNUTH, Liliane Redu. O método e o ensino da Geografia na Educação do campo. In: VI SEUR e III Colóquio Internacional Sobre as Cidades do Prata. Pelotas: UFPEL, 2010, p. 100-110.

MOLINA, Mônica Castagna. Reflexões sobre o significado do protagonismo dos movimentos sociais na construção de políticas públicas de Educação do Campo. In: MOLINA, M. C. (Org.). Educação do Campo e Pesquisa II. Brasília, MDA/MEC, 2010. p. 137-149.

MORAES, Antônio Carlos Robert. Renovação da Geografia e Filosofia da Educação. In: OLIVEIRA, A. U. de (Org.). Para onde vai o ensino de Geografia? São Paulo: Contexto, 1994, p. 117-134.

OLIVEIRA, Alexandra Maria de. Educação geográfica no projeto camponês de convivência com o semiárido. Geosaberes: revista de estudos geoeducacionais, Fortaleza, v. 6, n. 2, p. 46- 54, 2015.

OLIVEIRA, Guilherme Matos de. Traçados do cotidiano de pequenos sertanejos na aula de Geografia em uma escola camponesa na Bahia. Revista Brasileira de Educação em Geografia, Campinas, v. 10, n. 20, p. 591-602, 2020.

PONTUSCHKA, Nídia Nacib et al. Para ensinar e aprender Geografia. $3^{\text {a }}$ ed. São Paulo: Cortez, 2009.

SAVIANI, Dermeval. Escola e democracia: teorias da educação, curvatura da vara, onze teses sobre educação e política. 32a ed. São Paulo: Cortez/Autores Associados, 1999.

VESENTINI, José William. Geografia Crítica e Ensino. In: OLIVEIRA, A. U. de (Org.). Para onde vai o ensino de Geografia? São Paulo: Contexto, 1994, p. 30-38. 